$\begin{array}{rr}\text { JURNAL } & \text { Volume 13, Nomor 2, Maret 2017 } \\ \text { FIT(PATOLOGI } & \text { Halaman 67-71 } \\ \text { IN DON S IA } & \text { DOI: } 10.14692 / \text { jfi.13.2.67 } \\ \text { ISSN: } 0215-7950 & \end{array}$

KOMUNIKASI SINGKAT

\title{
Penyakit Busuk Akar dan Pangkal Batang Tebu di Sumatera Selatan
}

\section{Sugarcane Root and Basal Stem Rot Disease in South Sumatera}

\author{
Tri Maryono*, Ani Widiastuti, Achmadi Priyatmojo \\ Universitas Gadjah Mada, Yogyakarta 55281
}

\begin{abstract}
ABSTRAK
Penyakit busuk akar dan pangkal batang tebu yang disebabkan oleh Xylaria sp. merupakan salah satu penyakit baru diperkebunan tebu Indonesia. Sampai saat ini, penyakit busuk akar dan pangkal batang tebu hanya dilaporkan ada di Sumatera dan informasi mengenai penyakit ini masih terbatas. Penelitian dilakukan untuk mendeskripsikan gejala, tanda, dan pola sebaran penyakit di lapangan yang dapat digunakan sebagai dasar untuk menentukan keberadaan penyakit di lapangan. Survei gejala, tanda, dan pola sebaran penyakit dilakukan di perkebunan tebu yang terdapat di Sumatera Selatan $\left(3^{\circ} 26^{\prime} 16.6^{\prime \prime}\right.$ LS dan $104^{\circ} 40^{\prime} 09.8^{\prime \prime}$ BT). Gejala khas serangan Xyalaria sp. ialah tanaman tebu mengering seluruh daunnya dan mati, akar dan pangkal batang busuk kering, dan ratoon tidak tumbuh. Gejala tanaman tebu mati, tanda penyakit berupa stroma pada pangkal batang atau di tanah sekitar tanaman sakit, dan pola sebaran penyakit mengelompok merupakan indikator yang kuat mengenai keberadaan Xylaria di perkebunan tebu.
\end{abstract}

Kata kunci: pola sebaran, tanda penyakit, ratoon, Xylaria

\begin{abstract}
Root and basal stem rot disease caused by Xylaria sp. is a new diseases in Indonesian sugarcane plantation. The disease has been reported only occurred in sugarcane plantations in Sumatera. Limited information about the disease has slowed down disease diagnosis in the field. The research was aimed to describe symptoms, signs, and spatial distribution of the disease caused by Xylaria. A survey was conducted at a sugarcane plantation in South Sumatera ( $3^{\circ} 26^{\prime} 16.6^{\prime \prime} \mathrm{S}$ dan $104^{\circ} 40^{\prime} 09.8^{\prime \prime}$ E). Typical symptoms of the disease involved drying of all leaves and plant death, dry rot of root and basal stem, and retarded growth of ratoon cane were recorded. Stroma was found on surface of diseased stems and on soil surface of diseased plants, and spatial aggregation of diseased plants was observed in all locations. The distribution of the diseased plant aggregately and the presence of stroma on diseased plants are important characteristics of the disease diagnosis in sugarcane plantations.
\end{abstract}

Keywords: disease distribution, disease sign, ratoon, Xylaria

*Alamat penulis korespondensi: Jurusan Proteksi Tanaman, Fakultas Pertanian Universitas Lampung. Jalan Prof. Dr. Soemantri Brodjonegoro No. 1 Bandar Lampung, 35142.

Tel: 0721-787029, Faks: 0721-787029, Surel: tri.maryono@fp.unila.ac.id 
Penyakit busuk akar dan pangkal batang atau disebut penyakit lapuk akar dan pangkal batang atau juga disebut penyakit xylaria merupakan penyakit yang relatif baru di perkebunan tebu Indonesia. Penyakit tersebut pertama ditemukan pada tahun 1993 di perkebunan tebu PT Gunung Madu Plantation, Provinsi Lampung (Hersanti dan Sitepu 2005; Sitepu et al. 2010). Sampai saat ini penyakit hanya dilaporkan pada perkebunan tebu di Sumatera (Achadian et al. 2012). Selain di Indonesia, penyakit tersebut juga terdapat di Taiwan, Amerika Serikat, dan Puerto Rico (Fang dan Lee 2000). Penyakit xylaria yang ada di Lampung disebabkan oleh Xylaria cf warburgii (Sitepu et al. 2010), sama seperti yang di Taiwan (Fang et al. 1986). Namun, di Amerika Serikat dan Puerto Rico penyakit tersebut sebabkan oleh Xylaria arbuscula (Fang dan Lee 2000).

Penyakit busuk akar dan pangkal batang tebu memiliki arti ekonomi yang penting pada budi daya tebu karena dapat mematikan tanaman, menurunkan bobot batang, dan menurunkan rendemen. Selain itu juga mengakibatkan tanaman keprasan (ratoon cane) gagal tumbuh karena tanaman induknya mati. Kerugian tersebut akan lebih tinggi pada tanaman ratoon dibandingkan dengan tanaman dari bibit (plant cane) dan akan terus meningkat pada generasi tanaman ratoon berikutnya. Kerugian lainnya ialah apabila pada tanaman ratoon pertama serangannya tinggi maka harus dilakukan penanaman ulang (replanting) untuk menghindari kerugian yang lebih besar. Di Lampung keparahan penyakit $26 \%$ dapat menyebabkan penurunan hasil sampai 15\% (Sitepu et al. 2010).

Sampai saat ini, informasi mengenai penyakit xylaria masih terbatas karena belum banyak dikaji khususnya di Indonesia. Di sisi lain keberadaan penyakit xylaria relatif sulit untuk ditentukan terutama pada tanaman induk (Hersanti dan Sitepu 2005).

Survei penyakit xylaria dilakukan dari Juni-Agustus 2016 di perkebunan tebu di Sumatera Selatan $\left(3^{\circ} 26^{\prime} 16.6^{\prime \prime}\right.$ LS dan $104^{\circ}$ 40 '09.8" BT). Tanaman tebu yang diamati ialah tanaman ratoon varietas PS 882 berumur
9 bulan. Pengamatan dilakukan pada tiga petak yang berbeda dengan luas petak 10, 12.5, dan $16 \mathrm{Ha}$. Pengamatan gejala penyakit dilakukan secara visual meliputi gejala pada tajuk tanaman, gejala pada akar, dan gejala pada jaringan pangkal batang. Pengamatan gejala pada bagian akar dilakukan dengan mencabut tanaman sakit, sedangkan pengamatan gejala pada jaringan pangkal batang dilakukan dengan memotong secara membujur pangkal batang tanaman sakit. Pengamatan tanda penyakit juga dilakukan secara visual pada tanaman sakit dan sekitar tanaman sakit. Pengamatan pola sebaran penyakit dilakukan pada satu musim tanam dengan mengamati sebaran gejala kerusakan tanaman tebu di lapangan berupa tanaman ratoon yang tidak tumbuh. Pengamatan dilakukan pada dua titik pada masing-masing petak pengamatan. Untuk memastikan bahwa ratoon yang tidak tumbuh disebabkan oleh Xylaria maka keberadaan stroma Xylaria pada sekitar titik tersebut dijadikan dasarnya. Hasil pengamatan sebaran penyakit xylaria yang diperoleh dibandingkan dengan model pola sebaran penyakit yang dikemukakan Brown (1997).

Kegiatan survei yang dilakukan berhasil menemukan gejala penyakit xylaria pada tanaman tebu. Gejala yang ditemukan berupa gejala awal dan gejala akhir, yaitu matinya tanaman. Gejala awal penyakit ialah daun menguning dan mengering dari ujung daun (Gambar 1a). Seiring berjalannya waktu, semua daun akan mengering yang menandakan perakaran dan pangkal batang sudah rusak parah. Pada serangan berat, rumpun tanaman akan mengering dan mati (Gambar 1b). Tanaman yang mati mudah dicabut karena akarakarnya juga mati. Akar tanaman sakit tampak membusuk (busuk kering) dan berwarna hitam (Gambar 1d). Apabila pangkal batang tebu sakit dibelah maka jaringan pangkal batang tebu terlihat cokelat muda dan kemerahan, serta terdapat garis berwarna hitam (Gambar 1d) yang merupakan ciri khas serangan Xylaria. Apabila tanaman induk mengalami kerusakan yang berat atau mati maka tanaman ratoon tidak akan tumbuh sehingga akan tampak kosong dan dipenuhi gulma. 
Tanda penyakit berupa stroma berhasil ditemukan di lapangan pada batang tebu sakit dan tanah di sekitar tanaman tebu sakit (Gambar 2). Ada dua bentuk stroma yang berhasil ditemukan. Stroma yang pertama berwarna hitam, berkelompok dan bercabang banyak, dan bagian ujungnya berwarna putih (Gambar 2a). Stroma yang kedua berbentuk batang silindris dengan semakin meruncing keujungnya, tunggal, bertangkai pendek, berwarna hitam atau kecoklatan, dan tidak bercabang atau bercabang pada pangkalnya (Gambar 2b dan 2c). Adanya stroma merupakan salah satu ciri khas Xylaria (Ma et al. 2011; Srihanant et al. 2015; Huang et al. 2015)

Sebaran tanaman ratoon yang tidak tumbuh terlihat berkelompok pada semua titik pengamatan. Pada satu baris bisa terdapat banyak tanaman ratoon yang tidak tumbuh sedangkan pada baris sebelahnya hanya ada beberapa tanaman ratoon tidak tumbuh atau tumbuhsemua.Penyebaransecaraberkelompok mencirikan bahwa penyebab penyakit merupakan cendawan tular tanah, seperti yang dilaporkan oleh Stewart et al. (2014).

Hasil isolasi penyebab penyakit dari bagian tanaman sakit, setelah ditumbuhkan pada medium agar-agar dektrosa kentang, didapatkan cendawan yang awalnya berwarna putih yang akan berubah menjadi gelap yang dimulai dari bagian tengahnya (Gambar 3a). Pada biakan yang berumur lebih dari dua minggu akan tumbuh stroma yang bercabang banyak, yang awalnya berwarna putih, namun

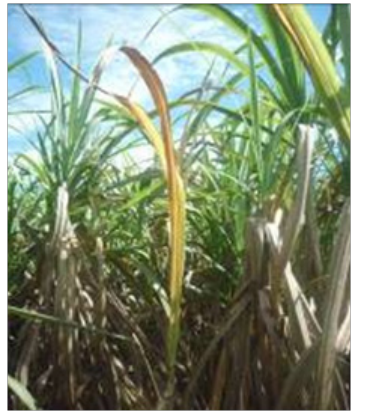

a

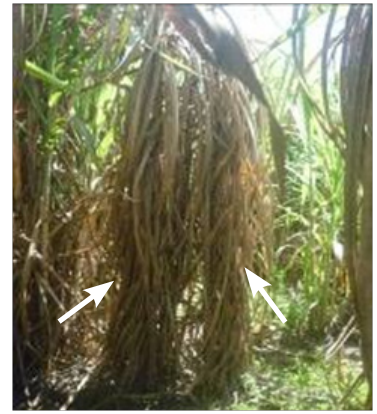

$\mathrm{b}$

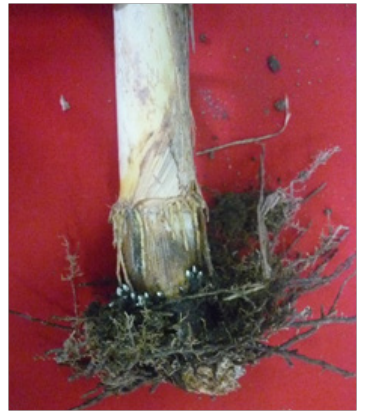

c

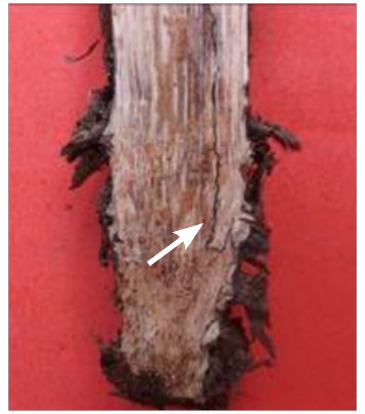

d

Gambar 1 Gejala penyakit xylaria pada tanaman tebu. a, Daun menguning dan mengering dari ujung daun; b, Rumpun tanaman tebu mati; c, Akar tanaman sakit yang tampak menghitam; dan $\mathrm{d}$, Penampang membujur pangkal batang tebu sakit dan massa hifa. Ciri khas serangan Xylaria sp ditunjukkan dengan tanda panah.

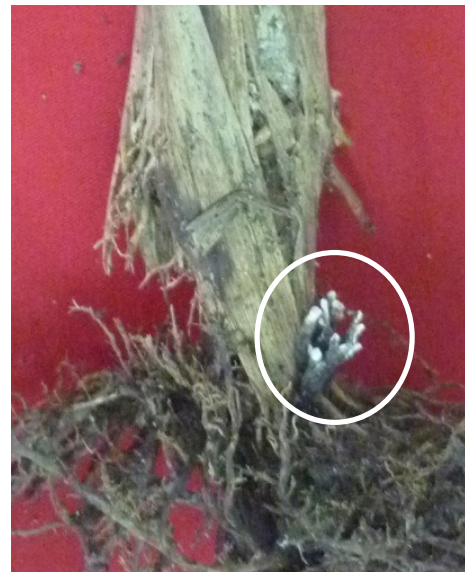

a

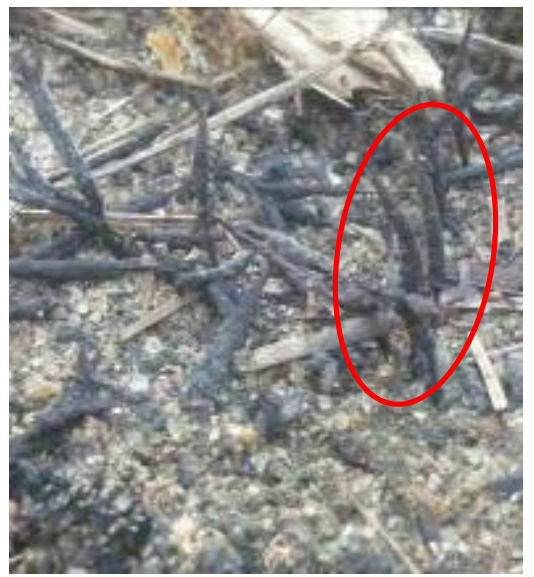

b

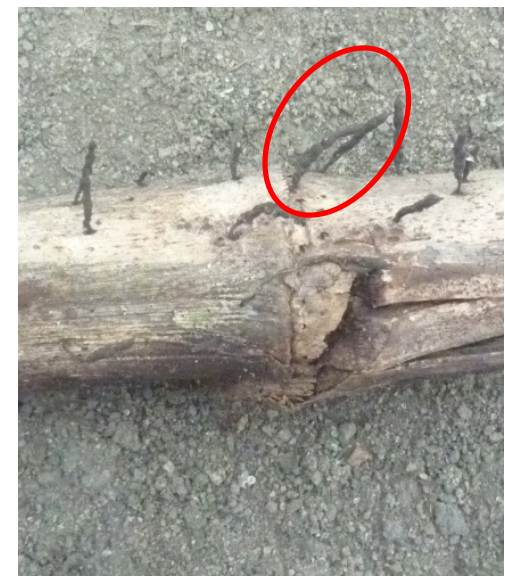

$\mathrm{C}$

Gambar 2 Stroma Xylaria sp. pada tanaman tebu. a, Stroma pada pangkal tanaman tebu sakit; b, Stroma yang keluar dari tanah di sekitar tanaman sakit; dan c, Stroma yang tumbuh dari sisasisa tanaman sakit. 


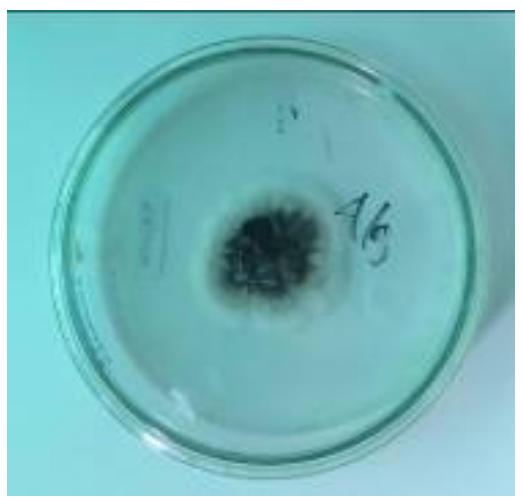

$\mathrm{a}$

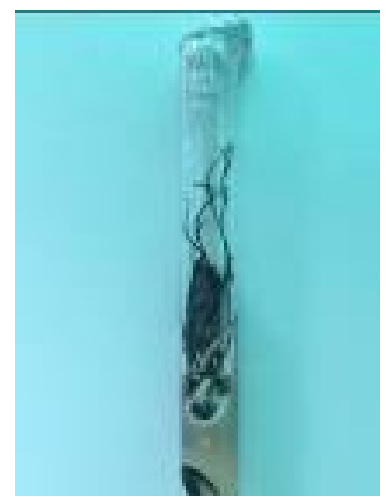

$\mathrm{b}$

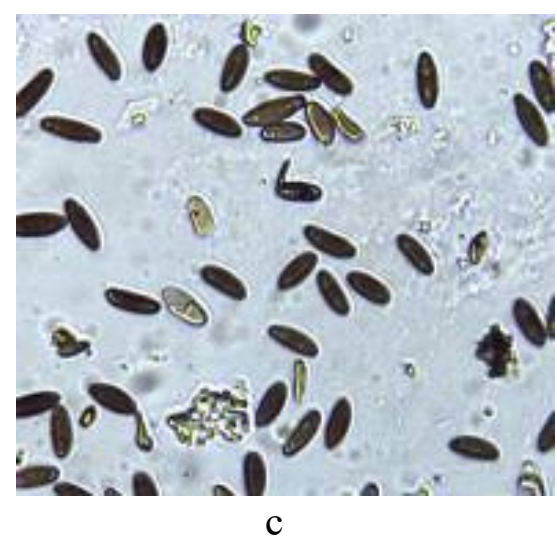

Gambar 3 Karakter morfologi penyebab Xylaria sp. pada tanaman tebu. a, Biakan cendawan Xylaria sp. pada medium agar-agar dekstrosa kentang; b, Stroma yang terbentuk pada medium agar-agar miring; dan c, Askospora (perbesaran 100×).

pada akhirnya berwarna hitam (Gambar 3b). Spora yang didapat dari stroma berbentuk lonjong dan berwarna hitam (Gambar 3c). Berdasar karakter morfologi tersebut, cendawan yang didapat adalah Xylaria sp. Secara umum Xylaria hidup sebagai saprob atau sebagai parasit lemah dan sedikit yang menjadi patogen (Whalley 1996), bersimbiosis dengan rayap (Rogers et al. 2005; Ju dan Hsieh 2007), dan sebagai endofit (Ibrahim et al. 2014).

Hasil survei ini menujukkan bahwa penyakit busuk akar dan pangkal batang tebu telah berkembang di perkebunan tebu di Sumatera Selatan. Adanya tanaman tebu yang mengering dan mati, adanya tanaman ratoon yang tidak tumbuh yang tersebar secara berkelompok dan adanya stroma pada pangkal batang tanaman sakit atau di tanah sekitar tanaman sakit dapat digunakan sebagai petunjuk adanya penyakit xylaria pada suatu perkebunan tebu.

\section{DAFTAR PUSTAKA}

Achadian E, Kristini A, Magarey R, Sallam N, Samson P, Goebel FR, Lonie K. 2012. Sugarcane pests and diseases-Field guide-Indonesian version. Indonesian Sugar Research Institute, BSES Limited, Australian Centre for International Research. Montpellier (FR): CIRAD.

Brown J. 1997. Survival and dispersal of plant parasites: general concepts. Di dalam: Brown JF, Ogle HJ, editor. Plant
Pathogens and Plant Diseases. New South Wales (AU): Rockvale Publication. Hlm 195-206.

Fang JG, Hsieh WH, Hu CH, Lee CS. 1986. Survival of Xylaria sp. in the soil and the effect of green manure application on disease incidence. Report of the Taiwan Sugar Research Institute. 112:21-26.

Fang JG, Lee CS. 2000. Root and basal stem rot. Di dalam: Rott P, Bailey RA, Comstock JC, Croft BJ, Saumtally AS, editor. A Guide to Sugarcane Diseases. Montpellier (FR): CIRAD-ISSCT. Hlm 170-173.

Hersanti, Sitepu R. 2005. Identifikasi penyebab penyakit lapuk akar dan pangkal batang (LAPB) tebu di PT Gunung Madu Plantations Lampung Tengah. Biotika. 4(1):24-27.

Huang G, Wang R, Guo L, Liu N. 2015. Three new species of Xylaria from China. Mycotaxon. 130:299-304. DOI: https:// doi.org/10.5248/130.299.

Ibrahim A, Sørensen D, Jenkins HA, McCarry BE, Sumarah, MW. 2014. New diplosporin and agistatine derivatives produced by the fungal endophyte Xylaria sp. isolated from Vitis labrusca. Phytochemistry Letters. 9:179-183. DOI: https://doi.org/10.1016/j. phytol.2014.06.011.

Ju YM, Hsieh HM. 2007. Xylaria species associated with nests of Odontotermes formosanusin Taiwan. Mycologia. 99:936957. DOI: http://dx.doi.org/10.1080/1557 2536.2007.11832525. 
Ma HX, Vasilyeva L, Li Y. 2011. A Srihanant N, Petcharat V, Vasilyeva LN. 2015. new species of Xylaria from China. Xylaria thailandica-a new species from Mycotaxon. 116:151-155. DOI: https:// Southern Thailand. Mycotaxon. 130:227doi.org/10.5248/116.151.

Rogers J, Ju Y-M, Lehmann J. 2005. Some Xylariaon termite nests. Mycologia. 97:914-923. DOI: http://dx.doi.org/10.10 80/15572536.2006.11832783.

Sitepu R, Sunaryo, Widyatmoko K, Purwoko H. 2010. Root and basal stem rot disease of sugarcane in Lampung, Indonesia. Di dalam: Prosiding Kongress XXVII International Society of Sugar Cane 231. DOI 10.5248/130.227.

Stewart LR, Morrison ML, Appel DN, Wilkins RN. 2014. Spatial and temporal distribution of Oak wilt in Golden-Cheeked Warbler habitat. Wildlife Soc Bull. 38(2):288-296. DOI: https://doi.org/10.1002/wsb.395.

Whalley AJS. 1996. The xylariaceous way of life. Mycol Res. 100:897-922. DOI: https:// doi.org/10.1016/S0953-7562(96)80042-6. Technologists; 2010 Mar 7-11; Veracruz (MX): ISSCT. hlm 1-7. 